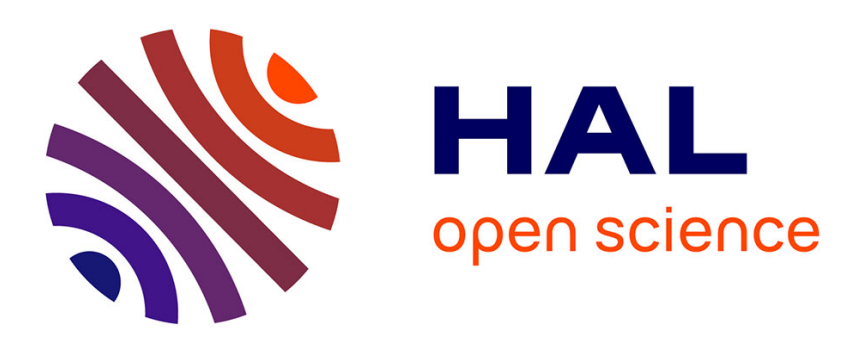

\title{
Integrating palaeontological and molecular data uncovers multiple ancient and recent dispersals in the pantropical Hamamelidaceae
}

Xiaoguo Xiang, Kunli Xiang, Rosa del C. Ortiz, Florian P Jabbour, Wei Wang

\section{- To cite this version:}

Xiaoguo Xiang, Kunli Xiang, Rosa del C. Ortiz, Florian P Jabbour, Wei Wang. Integrating palaeontological and molecular data uncovers multiple ancient and recent dispersals in the pantropical Hamamelidaceae. Journal of Biogeography, 2019, 46 (11), pp.2622-2631. 10.1111/jbi.13690 . hal-02612865

\section{HAL Id: hal-02612865 \\ https://hal.science/hal-02612865}

Submitted on 19 May 2020

HAL is a multi-disciplinary open access archive for the deposit and dissemination of scientific research documents, whether they are published or not. The documents may come from teaching and research institutions in France or abroad, or from public or private research centers.
L'archive ouverte pluridisciplinaire HAL, est destinée au dépôt et à la diffusion de documents scientifiques de niveau recherche, publiés ou non, émanant des établissements d'enseignement et de recherche français ou étrangers, des laboratoires publics ou privés. 
Integrating palaeontological and molecular data uncovers multiple ancient and recent dispersals in the pantropical Hamamelidaceae

\author{
Xiaoguo Xiang ${ }^{1,2}$, Kunli Xiang ${ }^{1,3}$, Rosa Del C. Ortiz ${ }^{4}$, Florian Jabbour ${ }^{5}$, Wei Wang ${ }^{1,3}$ \\ 1State Key Laboratory of Systematic and Evolutionary Botany, Institute of Botany, Chinese Academy of \\ Sciences, Beijing, China \\ 2Jiangxi Province Key Laboratory of Watershed Ecosystem Change and Biodiversity, Institute of Life Science \\ and School of Life Sciences, Nanchang University, Nanchang, China \\ 3University of Chinese Academy of Sciences, Beijing, China \\ 4Missouri Botanical Garden, St. Louis, MO, USA \\ 5Institut de Systématique, Evolution, Biodiversité, Muséum national d'Histoire naturelle, CNRS, Sorbonne \\ Universités, EPHE, Paris, France
}

Correspondence

Wei Wang, State Key Laboratory of Systematic and Evolutionary Botany, Institute of Botany, Chinese Academy of Sciences, 20 Nanxincun, Xiangshan, Beijing 100093, China.

Email: wangwei1127@ibcas.ac.cn

Funding information

Strategic Priority Research Program of the Chinese Academy of Sciences, Grant/Award Number: XDB31030000; National Natural Science Foundation of China, Grant/Award Number: 31470315, 31770231, 31300181,31770233 , and 31670212

\begin{abstract}
Aim: The integration of palaeontological and phylogenetic data can improve our understanding in the spatio-temporal evolutionary processes of living organisms. However, how best to use fossil data in divergence time estimation and ancestral range reconstruction remains challenging. Here, we integrated palaeontological and molecular data to investigate the historical biogeography of Hamamelidaceae, a pantropical angiosperm family with abundant fossils outside its present distribution.
\end{abstract}

Location: Global tropical/subtropical areas.

Methods: Using seven DNA regions (>7,500 bp) from plastid and nuclear genomes, we reconstructed a robust phylogenetic framework for Hamamelidaceae with the first complete genus-level sampling. We used the tip-dating method with the 22 fossils to estimate divergence times for the family, and inferred the ancestral range of lineages under the dispersal-extinction-cladogenesis model by incorporating the fossils.

Results: Our biogeographic analysis indicates that extant Hamamelidaceae most likely originated in tropical Asia during the mid-Cretaceous, and in the family 20 dispersals occurred during three major time intervals: the Upper Cretaceous (c. 93-69 Ma), Palaeocene-Eocene (c. 63-39 Ma) and late Oligocene (c. 27-23 Ma).

Main conclusions: Overland migrations through available land bridges and island chains may have been mainly responsible for hamamelidaceous range expansions during these three episodes. This study contributes to our knowledge on the assembly and evolution of angiosperm-dominated tropical and subtropical forests.

\title{
K E YWORDS
}

biogeography, divergence time estimates, fossil, Hamamelidaceae, phylogeny, tropical and subtropical forests

\section{INTRODUCTION}

A central goal of biogeography is to understand the geographic assembly of biodiversity through time (Cox \& Moore, 2005). Two relatively independent research fields, palaeontology and phylogenetics, have been used to address this theme. It is now commonly acknowledged that a better understanding of the history of living organisms and their ecological and evolutionary processes can be accomplished through the integration of palaeontological and phylogenetic data (Benton, 2015; Hunt \& Slater, 2016). The dominant role of fossil data in combination with molecular phylogenetics has been to serve as calibration points in dating analyses based on the 
assumed position of fossil taxa in the phylogenetic tree of extant taxa (Parham et al., 2012). Currently, the Bayesian uncorrelated relaxed clock method (Drummond, Ho, Phillips, \& Rambaut, 2006), implemented in beast (Drummond \& Rambaut, 2007), is widely used. This method may rely on fossil data to calibrate one or several nodes of the tree and is accordingly regarded as node-dating (Ronquist et al., 2012). However, multiple fossil taxa associated with a particular node in a tree of extant taxa need to be reduced to a single calibration point (Parham et al., 2012; Ronquist et al., 2012). Another important aspect to consider when integrating phylogenetic and palaeontological data into biogeography is the reconstruction of ancestral ranges by combining information of fossil and living taxa. For a group with fossil taxa outside its modern distribution, the inclusion of fossil taxa can heavily influence its biogeographic reconstructions (Manchester \& Tiffney, 2001; Mao et al., 2012; Meseguer, Lobo, Ree, Beerling, \& Sanmartín, 2015). Generally, fossil taxa can be directly placed in the phylogenetic trees of extant taxa based on the appearance time and can thereby be included in inferences of ancestral ranges (e.g. Clayton, Soltis, \& Soltis, 2009; Mao et al., 2012; Zhang et al., 2013). However, this strategy can sometimes be problematic. For example, if two or more fossils belonging to a single clade are contemporaneous, based only on the appearance time, their placements will result in a polytomy for the lower clade (zero-length branch).

The recently developed tip-dating (TD) method estimates divergence times with all available fossil taxa as terminal tips based on morphological or combined morphological and molecular data (Pyron, 2011; Ronquist et al., 2012). This method can thereby generate a dated phylogeny containing extinct and extant taxa, or even entirely extinct taxa and overcome zero-length branches to a certain extent. Moreover, in comparison with node dating, TD method may establish direct calibrations using the known age of the fossils, and accommodates the uncertainty of their phylogenetic position through the co-estimation of time and topology (O'Reilly, dos Reis, \& Donoghue, 2015). Therefore, TD can avoid some arbitrary settings of prior calibration points, and yield more accurate age estimates while providing a coherent measure of statistical uncertainty (Heath, Huelsenbeck, \& Stadler, 2014).

Tropical and subtropical forests are well-known as the most species-rich and productive terrestrial biomes on Earth. How the past biogeographic events have shaped their present distribution pattern, diversification and endemism has long been the quest in biology and ecology (Emerson \& Kolm, 2005). Several studies focused on the temporal patterns of the origin and evolution of angiosperm- dominated forests (e.g. Couvreur, Forest, \& Baker, 2011; Davis, Webb, Wurdack, Jaramillo, \& Donoghue, 2005; Wang et al., 2009; Yu et al., 2017). A few studies have investigated spatial patterns of tropical angiosperm lineages in the early Tertiary, a warming period (e.g. Bartish, Antonelli, Richardson, \& Swenson, 2011; Davis, Bell, Mathews, \& Donoghue, 2002; Lian, Xiang, Ortiz, \& Wang, 2019). Evidence from fossil and molecular data suggests that angiosperm- dominated tropical forests arose in the mid-Cretaceous (e.g. Couvreur et al., 2011; Davis et al., 2005; Morley, 2007; Upchurch \& Wolfe, 1993; Wang et al., 2009). To better understand spatio-temporal patterns and processes underlying the distribution of biodiversity in tropical forests, one needs to investigate biogeographic events of an ancient group on a worldwide basis.

In this study, we focus on the historical biogeography of the angiosperm family Hamamelidaceae. During the past years, molecular phylogenetic studies have re-delimitated this family, where the subfamily Altingioideae was excluded and raised to the familial rank as Altingiaceae (e.g. Ickert-Bond \& Wen, 2013; Jian et al., 2008; Stevens, 2001). As currently circumscribed, Hamamelidaceae contains 28 genera and c. 120 species (Judd, Campbell, Kellogg, Stevens, \& Donoghue, 2007), which are small shrubs or trees of great ecological importance inhabiting tropical and subtropical forests worldwide, with Hamamelis extending to temperate regions (Ohsawa, 1991; Wu, Lu, Chen, \& Li, 2003; Ying \& Chen, 2011; Figure S1). Hamamelidaceae is well-known for its broad and scattered geographic distribution and its endemics (Endress, 1993; Zhang \& Lu, 1995). The majority of genera are geographically restricted except for Hamamelis which shows a disjunct distribution between eastern North America and eastern Asia (Figure 1). The fruits of Hamamelidaceae are woody dehiscent capsules (Endress, 1993). Seeds are usually dispersed by a ballistic mechanism, and hence are not expected to disperse across long distances or oceanic barriers even though seeds of Exbucklandia and Rhodoleia have small narrow wings (Endress, 1993). The oldest fossil flowers of the family come from the late Santonian of North America and Europe (c. $84 \mathrm{Ma}$; Endress \& Friis, 1991). Recent molecular clock estimates suggest a stem age of c. 84-100 Ma for the family (Jian et al., 2008) or 95.93 Ma (90.99-104.04; Magallón, Gómez-Acevedo, Sánchez-Reyes, \& Hernández-Hernández, 2015). Fossil evidence indicates that Hamamelidaceae were widely distributed in the Northern Hemisphere in the Upper Cretaceous (Figure 1; Zhang \& Lu, 1995). The family has an abundant fossil record in the early Tertiary, with representation of many extant and extinct genera (reviewed by Manchester, Chen, Lu, \& Uemura, 2009; Zhang \& Lu, 1995). Importantly, most of the fossils are distributed outside the modern ranges of the taxa to which they have been assigned (Figure 1). Thus, Hamamelidaceae provides an 
opportunity to investigate historical biogeography of living organisms through the integration of palaeontological and molecular phylogenetic data.

Here, we first infer the phylogeny of Hamamelidaceae with complete genus-level sampling. With the resulting phylogenetic framework, we then estimate divergence times for the family using the TD method with 22 fossils and investigate the historical biogeography of the family by incorporating the fossils. Given the Cretaceous age and widespread distribution of Hamamelidaceae, a weak seed dispersal ability, the restriction of most genera to particular tropical regions, as well as an abundant fossil record, this study may provide new insights into the past tropical floristic exchanges among different continents.

\title{
MATERIALS AND METHODS
}

\section{Taxon sampling and DNA sequencing}

We sampled 55 taxa of Hamamelidaceae, representing all 28 of the currently recognized extant genera of the family; the genus Embolanthera, endemic to southeastern Asia, was included in a molecular phylogenetic analysis for the first time. Based on Jian et al. (2008) and Soltis et al. (2011), we selected 14 species from close relatives of Hamamelidaceae as outgroups: three species from its sister clade DaphniphyllaceaeCercidiphyllaceae, 10 species from Altingiaceae and one species of Paeoniaceae. Six plastid (atpB, matK, rbcL, atpB-rbcL, trnH-psbA and trnLUAA-FGAA) and one nuclear (ITS) DNA region were used in this study. Voucher information and GenBank accession numbers are listed in Table S2.

Total genomic DNA was extracted from fresh silica gel-dried leaves or herbarium specimens using DNeasy Mini Plant Kits (Tiangen Biotech). The selected DNA regions were amplified with standard polymerase chain reaction (PCR). The primers used in this study are listed in Table S3. Sequencing reactions were conducted using the ABI Prism BigDye Terminator Cycle Sequencing Kit (Applied Biosystems, ABI). Products were analysed on ABI 3730xl automated DNA sequencers.

\begin{abstract}
Alignment and phylogenetic analysis
Sequences were aligned using the default parameters in Clustal X 1.83 (Thompson, Gibson, Plewniak, Jeanmougin, \& Higgins, 1997) and manually adjusted with BioEdit 5.0.9 (Hall, 1999). After excluding ambiguous regions, we obtained a concatenated alignment of 7,549 bp for 69 taxa (Table S4). Phylogenetic analyses were carried out using maximum parsimony (MP) and Bayesian inference (BI) methods in paup $4.0 \mathrm{~b} 10$ (Swofford, 2003) and MrBayes 3.2.6 (Ronquist et al., 2012) respectively. For MP analyses, heuristic searches were performed with 1,000 random sequence addition replicates, tree-bisection-reconnection (TBR) branch swapping, MulTrees in effect and steepest descent off. Gaps were treated as missing data, characters were equally weighted and their states were unordered. Internal branch support was estimated by using 1,000 bootstrap replicates as described above. For BI analyses, each DNA region was assigned its own model of nucleotide substitution (Table S4), as determined by the Akaike information criterion (AIC) in Modeltest 3.06 (Posada \& Crandall, 1998). Four chains of the Markov chain Monte Carlo (MCMC) were run, sampling one tree every 1,000 generations for 3,000,000, starting with a random tree. Majority-rule (> 50\%) consensus trees were constructed after removing the burn-in period samples (the first $25 \%$ of sampled trees).
\end{abstract}

\section{Divergence time estimation}

Data about the fossil records of Hamamelidaceae were gathered from the literature and from the Paleobiology Database (http://paleo db.org/). We selected only the fossils that could be confidently attributed to specific taxonomic groups. A total of 19 hamamelidaceous fossils were used to estimate divergence times and reconstruct biogeographic scenarios. One fossil from Cercidiphyllaceae and two fossils from Altingiaceae were also included. Justifications of the ages and placements of the 22 fossils are given in Table S1. A likelihood ratio test was first carried out to estimate whether Hamamelidaceae evolved at a homogeneous rate along all branches of the phylogeny. The result rejected a constant rate for the family $(\delta=1503.14$, df $=67, \mathrm{p}<0.0001)$. Thus, we estimated divergence times of Hamamelidaceae using TD method with a Bayesian relaxedclock model.

We first constructed a matrix containing 69 extant and 22 fossil taxa. The molecular data for fossils are coded as missing, and in total 68 morphological characters for 91 taxa were included (Table S5). The majority-rule consensus tree from the BI analysis was used and fossil taxa were placed in the relevant clades based on apomorphy-based or phylogenetic methods (Sauquet et al., 2012; Table S1). Divergence time estimation was performed in MrBayes 3.2.6 under a fossilized birth-death (FBD) prior process (Heath et al., 2014), with a lognormal prior and an uncorrelated independent gamma rates model. The calibrated ages of the 22 internal fossils were assigned a uniform prior distribution with ranges corresponding to the age ranges of their respective geological strata. To avoid overestimation of root age, we set a maximum age of $112.99 \mathrm{Ma}(\mathrm{sd}=0.5)$ for the root, which is the crown group age of Saxifragales (Magallón et al., 2015). Morphological data were analysed 
under the Mk model (Lewis, 2001). For the molecular partitions, each DNA region was assigned an unlinked substitution model (Table S4). Two independent MCMC runs were carried out, every run with 100 million generations and sampling trees every 5,000 generations. Convergence was evaluated as described in the beast analyses, and in each MCMC run, the first 10 million generations of the samples were discarded as burn-in.

\section{Biogeographic analysis}

Ancestral area reconstructions (AARs) were conducted using a recently developed Statistical BioGeoBEARS (S-BioGeoBEARS), implemented in rasp 4.0 (Matzke, 2013; Yu, Harris, Blair, \& He, 2015). Ree and Sanmartín (2018) suggest that the biogeographic models with $+\mathrm{J}$ parameter (founder-event speciation) have conceptual and statistical problems. The dispersal-extinction-cladogenesis model (DEC; Ree \& Smith, 2008) was used here. Following Buerki et al. (2011), we specified dispersal probabilities between pairs of areas for four separate time slices (Table S6).

According to current and fossil distributions of Hamamelidaceae, species sampled were assigned to one or more of the following seven biogeographic regions: tropical Asia, East Palaearctic, Oceania, Africa, Europe (including western Asia), North America and Central America (including southern Mexico and northern South America) (Figure 1). We randomly sampled 1,000 timetrees generated from MrBayes as a 'tree file' and used the majority-rule consensus tree derived from the MCMC stationary sample as a final representative tree.

\section{RESULTS}

\section{Phylogeny}

MP and BI analyses resulted in highly congruent trees (Figure S2). The phylogeny we inferred for Hamamelidaceae is the most taxonomically complete to date, and includes all genera recognized at present. Hamamelidaceae and each of its four subfamilies are all strongly supported as monophyletic. Exbucklandioideae is the earliest-diverging lineage $(\mathrm{BS}=100 \%, \mathrm{PP}=1.00)$, followed by Mytilarioideae $(\mathrm{BS}=100 \%, \mathrm{PP}=1.00)$. Within the family, relationships among the subfamilies are consistent with the results of Li (2008), but are usually resolved with greater support for clades found therein. Within Hamamelidoideae, each of Fothergilleae, Hamamelideae, Dicorypheae and Eustigmateae is strongly supported as monophyletic, while Loropetaleae is paraphyletic, with Embolanthera recovered as sister to Corylopsideae $(\mathrm{BS}=54 \%, \mathrm{PP}=1.00)$. The majority of intergeneric relationships in the family are well resolved.

\section{Divergence times}

The dated phylogenetic tree is presented in Figure S3. The stem group age of Hamamelidaceae was estimated at 108.43 Ma (95\% HPD: 104.08-111.98; node 1). The Exbucklandioideae separated from the remaining Hamamelidaceae at 105.62 Ma (95\% HPD: 101.34-110.07; node 2), and Mytilarioideae occurred at $102.58 \mathrm{Ma}$ (95\% HPD: 98.91-107.81; node 10). The split of Disanthoideae and Hamamelidoideae was estimated at 100.03 Ma (95\% HPD: 96.05-104.16; node 13). The crown-group age of Hamamelidoideae is 97.2 Ma (95\% HPD: 92.93-101.68; node 16). The split of Dicorypheae and Eustigmateae was at 63.83 Ma (95\% HPD: 43.86-85.14; node 18). Central American Molinadendron split from its Asian sister group at 26.98 Ma (95\% HPD: 12.3741.21; node 20). The clade including Australian Ostrearia, Neostrearia and Noahdendron split from their African sister group at 39.83 Ma (95\% HPD: 23.03-58.49; node 26). North American and Asian Hamamelis split at 23.48 Ma (95\% HPD: 12.25-37.11; node 33). Fothergilla separated from the rest of Fothergilleae at $74.9 \mathrm{Ma}$ (95\% HPD: 64.09-86.21; node 37). European Parrotia and its Asian sister group separated at $41.18 \mathrm{Ma}(95 \%$ HPD: 26.21- 56.37; node 44). Matudaea a nd its A sian sister group diverged at 42.35 Ma (95\% HPD: 27.659.34; node 56).

\section{Biogeographic analyses}

The DEC model estimated the dispersal rate (d) as 0.0008 , and the extinction rate (e) as 0.0002 . The distribution of Hamamelidaceae is inferred to be the result of 20 dispersal events (Figure 2): six times from tropical Asia to North America (nodes 5, 29, 31, 33, 52, 60), four of which led to extinct branches; four from tropical Asia to Europe (nodes 7, 12, 56, 61), all of which led to extinct lineages; one from tropical Asia to Central America (node 20); one from tropical Asia to Africa (node 18); one from Africa to Oceania (node 26); one from tropical Asia to East Palaearctic (node 63); one from Europe to Central America (node 57); two from North America to East Palaearctic (nodes 37, 40), one of which led to an extinct branch (node 40); one from North America to Europe (node 30); one from East Palaearctic to tropical Asia (node 44); and one from East Palaearctic to Europe (node 45). The MRCA of Hamamelidaceae as well as of each of its four subfamilies were inferred to be distributed in tropical Asia.

\section{DISCUSSION}


Our inferred age estimation of the hamamelidaceous stem group ranges between 108.43 and $113.68 \mathrm{Ma}$, which is much older than previous estimates (84-100 Ma in Jian et al., 2008; 95.93 Ma in Magallón et al., 2015). Previous studies had a limited taxon sampling for Hamamelidaceae and/or no hamamelidaceous fossil calibrations were used. Similar older ages were produced for Fagales (Xiang et al., 2014) and Ranunculaceae (Wang et al., 2016) when more taxa and fossils were included. Internal calibrations and dense taxon sampling have been regarded to be vital to obtain accurate time estimates (Jian et al., 2008; Yang \& Rannala, 2006). Our analyses indicate that the split of Hamamelidaceae and its sister group occurred at 108.43 Ma (95\% HPD: 104.08-111.98; node 1) and the MRCA of Hamamelidaceae was likely present in tropical Asia by the mid-Cretaceous (node 2; Figure 2). This result supports the hypothesis of Takhtajan (1969) that this family originated in the southeastern Asian continent, rather than the eastern Asia-western North America origin as hypothesized by Wolfe (1974).

Our biogeographic reconstruction shows that at least 20 dispersals need to be invoked to explain the current distribution of Hamamelidaceae and that of the fossils attributed to it. Despite the uncertainty involved in any estimate using a molecular clock, based on our estimated median ages, these 20 dispersals occurred during three major episodes: five in the Upper Cretaceous (c. 93-69 Ma), nine in the Palaeocene-Eocene (c. 63-39 Ma) and six in the late Oligocene (c. 27-23 Ma) (Figure 3).

Among the five migration events inferred in Hamamelidaceae during the Upper Cretaceous, two occurred from tropical Asia to North America (node 29, 52), and one from North America to East Palaearctic (node 37). Palynological data suggest that during the Upper Cretaceous the Northern Hemisphere could be divided into two distinctive floras with different climates: the Normapolles flora (including eastern North America and Europe) and the Aquilapollenites flora (including major parts of Asia and western North America) (Wolfe, 1975; Zhou, 1986). It has been documented that the Turgai Strait might have been a barrier to plant migration between Asia and Europe by the middle Upper Cretaceous (Lomolino, Riddle, \& Brown, 2006). On the other hand, Graham (2018) has suggested that the exchange of plant populations between North America and Asia might have occurred via the Bering land bridge (BLB) in the Upper Cretaceous. Hamamelidaceous remains have been found in Siberia and the Amuro-Zeya Depression of North Asia during the Turonian (Maslova, Golovneva, \& Tekleva, 2005). Thus, the BLB may have played an important role in biotic exchange between Asia and North America for Hamamelidaceae during the Upper Cretaceous. Our results indicate that one migration occurred from North America to Europe (node 30) during the same period. Both of these two areas belong to the Normapolles flora (Wolfe, 1975), and the migration route across the North Atlantic was supported by the Cretaceous fossil records of Hamamelidaceae (Figure 1). In addition, one migration occurred from tropical Asia to Europe (node 7) in the late Upper Cretaceous, perhaps facilitated by the land bridge along the closing Tethys seaway that connected southern Europe and southwestern and southeastern Asia (Scotese, 2004; Tiffney \& Manchester, 2001). The fossil record of Hamamelidaceae from southwestern Europe supports this route (Endress \& Friis, 1991).

Nine migration events were inferred to have occurred during the Palaeocene-Eocene. Among them, three are from tropical Asia to Europe (nodes 12, 56, 61), two are from tropical Asia to North America (nodes 31, 60) and one is from East Palaearctic to Europe (node 45). The Asian precursors might have gradually migrated along the island chain of the Tethys seaway into southern Europe (Heaney, 2004). This migration route was also suggested for Alangium sect. Marlea (Alangiaceae) during the similar period (Feng, Manchester, \& Xiang, 2009). Hamamelidaceae expanded further westwards to North and Central America through the North Atlantic Land Bridge (NALB), which extended south to roughly $45^{\circ}$ and could have maintained sufficient warmth, light and humidity for thermophilic broadleaved evergreen plants to flourish (Tiffney \& Manchester, 2001). In the early Palaeocene, one lineage migrated from Asia to Africa (node 18). Many 'stepping-stone' chains in the Tethys Sea (Scotese, 2004) could have facilitated floristic exchange between Laurasia and Africa. A similar migration route from southeastern Asia into Africa during the Palaeocene was suggested for Alangium (Feng et al., 2009) and Cucurbitaceae (Schaefer, Heibl, \& Renner, 2009). Within Asia, one migration is also inferred from East Palaearctic to tropical Asia (node 44). The Palaeocene-Eocene largely coincides with the time of dominance of the boreotropical flora (Wolfe, 1975), which may have facilitated exchanges of thermophilic plants in the Northern Hemisphere.

The divergence time of the African-Oceanian disjunction in Hamamelidaceae was estimated to have occurred at c. $39.83 \mathrm{Ma}$ (node 26), which is long after the fragmentation of eastern Gondwana (c. 95-84 Ma; McLoughlin, 2001). A similar African-Oceanian disjunction was reported in Monimiaceae (Renner, Strijk, Strasberg, \& Thébaud, 2010) and Adansonia (Bombacaceae) (Wickens, 1983). The seeds of Hamamelidaceous plants with a ballistic dispersal mechanism could be dispersed over only short distances. However, the very hard exocarps may be able to maintain the viability of the seed if they are dispersed over longer distances by water (Endress, 
1993). Therefore, we hypothesize that Hamamelidaceae could have migrated from Africa to Oceania by transoceanic dispersal in the late Eocene.

Six migration events occurred during the late Oligocene. Among

these six events, two are from tropical Asia to North America (nodes

5, 33) and one is from North America to East Palaearctic (node 40). Two similar and contemporaneous biotic exchanges were also reported in Malpighiaceae (Davis, Fritsch, Bell, \& Mathews, 2004). In addition, we inferred one migration from tropical Asia to Central America (node 20) and one from Europe to Central America (node 57) during this period. In Ampelopsis (Vitaceae), Nie et al. (2012) found that migration from North America into both Europe and Asia took place during the early Miocene, and suggested a role of the NALB in enabling those migrations. Evidence from geology and palaeontology also support the idea that the NALB might have acted as a dispersal corridor for tropical or warm temperate floras in the early Eocene to middle Miocene (Tiffney, 1985). Thermophilic broadleaved evergreen elements, such as Hamamelidaceae, Malpighiaceae and Vitaceae, could thus have migrated between Eurasia and tropical America through the NALB during the late Oligocene and early Miocene. Within Asia, one migration is also inferred from tropical Asia to East Palaearctic (node 63). In the late Oligocene, global climate became warming (Zachos, Dickens, \& Zeebe, 2008), which may have driven range expansion of thermophilic lineages.

In conclusion, our integration of fossil and phylogenetic data indicate that extant Hamamelidaceae likely extend back to the mid- Cretaceous of tropical Asia and that shortly afterwards four major subfamilies diversified in tropical Asia about 105-97 Ma. A similar diversification pattern is found in the early evolutionary history of pantropical Arecaceae (Couvreur et al., 2011) and Menispermaceae (Wang et al., 2012), both of which are important components of modern tropical forests. Thus, our data for Hamamelidaceae suggest that Laurasia, especially tropical Asia, is not only a key source region, but also an important area where some plant families currently inhabiting tropical and subtropical forests might have diversified. Our findings further indicate that the range expansions of Hamamelidaceae occurred during three major episodes: the Upper Cretaceous, PalaeoceneEocene and late Oligocene. Several key angiosperm elements of tropical and subtropical forests, such as Annonaceae (Thomas et al., 2015), Malpighiaceae (Davis et al., 2004) and Menispermaceae (Wang et al., 2012), also appear to have expanded their ranges during one or two of these three episodes. Thus, we assume that these three episodes might also have been vital for the evolution and assembly of angiosperm-dominated tropical and subtropical forests. Yet, Hamamelidaceae is only one of many important components of angiosperm- dominated tropical and subtropical forests. This hypothesis needs to be further tested by studying other anciently thermophilic angiosperm groups in a broad phylogenetic context.

\section{ACKNOWLEDGEMENTS}

We sincerely thank Peter F. Stevens for kindly reading an earlier version of this manuscript, Shengxiang Yu for providing plant photos and Anmin Lu for his encouragement and valuable suggestions. We also thank the associate editor Richard Ree and four anonymous referees for their comments and invaluable suggestions that greatly improved our manuscript. This research was supported by the Strategic Priority Research Program of the Chinese Academy of Sciences (XDB31030000) and National Natural Science Foundation of China (31470315, 31770231, 31300181, 31770233, and 31670212).

\section{CONFLICT OF INTEREST}

The authors declared that they have no conflicts of interest in this work.

\section{DATA AVAILABILITY STATEMENT}

The sequences reported in this paper have been deposited in the GenBank database (accession nos. MG846141MG846212). The datasets can be archived in Dryad Digital Repository (https ://doi.org/10.5061/dryad.20v30sm).

Title: Data from: Integrating palaeontological and molecular data uncovers multiple ancient and recent dispersals in the pantropical Hamamelidaceae

DOI: doi:10.5061/dryad.20v30sm

Journal: Journal of Biogeography

Journal manuscript number: JBI-18-0528

\section{ORCID}

Xiaoguo Xiang https://orcid.org/0000-0003-2587-4153 
Rosa Del C. Ortiz https://orcid.org/0000-0002-4673-4347

Florian Jabbour https://orcid.org/0000-0002-7729-1067

Wei Wang https://orcid.org/0000-0001-6901-6375

\section{REFERENCES}

Bartish, V., Antonelli, A., Richardson, J. E., \& Swenson, U. (2011). Vicariance or long-distance dispersal: Historical biogeography of the pantropical subfamily Chrysophylloideae (Sapotaceae). Journal of Biogeography, 38, 177-190. https ://doi.org/10.1111/j.1365-2699.2010.02389.x

Benton, M. J. (2015). Exploring macroevolution using modern and fossil data. Proceedings of the Royal Society B: Biological Sciences, 282, 20150569. https ://doi.org/10.1098/rspb.2015.0569

Buerki, S., Forest, F., Alvarez, N., Nylander, J. A. A., Arrigo, N., \& Sanmartín, I. (2011). An evaluation of new parsimony based versus parametric inference methods in biogeography: A case study using the globally distributed plant family Sapindaceae. Journal of Biogeography, 38, 531-550. https ://doi.org/10.1111/j.13652699.2010.02432.x

Clayton, J. W., Soltis, P. S., \& Soltis, D. E. (2009). Recent long-distance dispersal overshadows ancient biogeographical patterns in a pantropical angiosperm family (Simaroubaceae, Sapindales). Systematic Biology, 58, 395-410. https ://doi.org/10.1093/sysbi o/syp041

Couvreur, T. L. P., Forest, F., \& Baker, W. J. (2011). Origin and global diversification patterns of tropical rain forests: Inferences from a complete genus-level phylogeny of palms. BMC Biology, 9, 44. https ://doi.org/10.1186/1741-7007-9-44

Cox, C. B., \& Moore, P. D. (2005). Biogeography: An ecological and evolutionary approach, 7th ed. Oxford: Blackwell Publishing.

Davis, C. C., Bell, C. D., Mathews, S., \& Donoghue, M. J. (2002). Laurasian migration explains Gondwanan disjunctions: Evidence from Malpighiaceae. Proceedings of the National Academy of Sciences USA, 99, 68336837. https ://doi.org/10.1073/pnas.10217 5899

Davis, C. C., Fritsch, P. W., Bell, C. D., \& Mathews, S. (2004). High-latitude Tertiary migrations of an exclusively tropical clade: Evidence from Malpighiaceae. International Journal of Plant Sciences, 165, S107S121. https ://doi.org/10.1086/383337

Davis, C. C., Webb, C. O., Wurdack, K. J., Jaramillo, C. A., \& Donoghue, M. J. (2005). Explosive radiation of Malpighiales supports a mid- Cretaceous origin of modern tropical rain forests. The American Naturalist, 165, E36-E65. https ://doi.org/10.1086/428296

Drummond, A. J., Ho, S. Y., Phillips, M. J., \& Rambaut, A. (2006). Relaxed phylogenetics and dating with confidence. PLoS Biology, 4, e88. https :// doi.org/10.1371/journ al.pbio.0040088

Drummond, A. J., \& Rambaut, A. (2007). BEAST: Bayesian evolutionary analysis by sampling trees. BMC Evolutionary Biology, 7, 214. https :// doi.org/10.1186/1471-2148-7-214

Emerson, B. C., \& Kolm, N. (2005). Species diversity can drive speciation. Nature, 434, 1015-1017. https ://doi.org/10.1038/natur e03450

Endress, P. K. (1993). Hamamelidaceae. In K. Kubitzki, J. G. Rohwer, \& V. Bittrich (Eds.), The families and genera of vascular plants, Vol. II (pp. 322-331). Berlin: Spring-Verlag.

Endress, P. K., \& Friis, E. M. (1991). Archamamelis, hamamelidalean flowers from the Upper Cretaceous of Sweden. Plant Systematics and Evolution, 175, 101-114. https ://doi.org/10.1007/BF009 42149

Feng, C. M., Manchester, S. R., \& Xiang, Q. Y. (2009). Phylogeny and biogeography of Alangiaceae (Cornales) inferred from DNA sequences, morphology, and fossils. Molecular Phylogenetics and Evolution, 51, $201-214$. https ://doi.org/10.1016/j.ympev.2009.01.017

Graham, A. (2018). The role of land bridges, ancient environments, and migrations in the assembly of the North American Flora. Journal of Systematics and Evolution, 56, 405-429. https ://doi.org/10.1111/jse.12302

Hall, T. A. (1999). BioEdit: A user-friendly biological sequence alignment editor and analysis program for Windows 95/98/NT. Nucleic Acids Symposium Series, 41, 95-98.

Heaney, L. R. (2004). Conservation biogeography in oceanic archipelagoes. In M. V. Lomolino, \& L. R. Heaney (Eds.), Frontiers of biogeography: New directions in the geography of nature (pp. 345-360). Cambridge, UK: Cambridge University Press.

Heath, T. A., Huelsenbeck, J. P., \& Stadler, T. (2014). The fossilized birth-death process for coherent calibration of divergence-time estimates. Proceedings of the National Academy of Sciences USA, 111, E2957-E2966. https ://doi.org/10.1073/pnas.1319091111

Hunt, G., \& Slater, G. (2016). Integrating paleontological and phylogenetic approaches to macroevolution. Annual Review of Ecology, Evolution and Systematics, 47, 189-213. https ://doi.org/10.1146/annur ev-ecolsys112414-054207

Ickert-Bond, S. M., \& Wen, J. (2013). A taxonomic synopsis of Altingiaceae with nine new combinations. PhytoKeys, 39, 512-528. https ://doi.org/10.3897/phyto keys.31.6251 
Jian, S., Soltis, P. S., Gitzendanner, M. A., Moore, M. J., Li, R., Hendry, T. A., ... Soltis, D. E. (2008). Resolving an ancient, rapid radiation in Saxifragales. Systematic Biology, 57, 38-57. https ://doi.org/10.1080/10635 150801888871

Judd, W. S., Campbell, C. S., Kellogg, E. A., Stevens, P. F., \& Donoghue, M. J. (2007). Plant systematics: a phylogenetic approach, 2nd ed., (pp. 343-344). Sunderland, MA: Sinauer Associates.

Lewis, P. O. (2001). A likelihood approach to estimating phylogeny from discrete morphological character data. Systematic Biology, 50, 913-925. https ://doi.org/10.1080/10635 15017 53462876

Li, J. H. (2008). Molecular phylogenetics of Hamamelidaceae: Evidence from DNA sequences of nuclear and chloroplast genomes. In A. K. Sharma, \& A. Sharma (Eds.), Plant genome biodiversity and evolution, Vol. 1 (pp. 227-250). Delhi: Science Publishers.

Lian, L., Xiang, K. L., Ortiz, R. D. C., \& Wang, W. (2019). A multi-locus phylogeny for the Neotropical Anomospermeae (Menispermaceae): Implications for taxonomy and biogeography. Molecular Phylogenetics and Evolution, 139, 44-52. https ://doi.org/10.1016/j.ympev.2019.04.006

Lomolino, M. V., Riddle, B. R., \& Brown, J. H. (2006). Biogeography, 3rd ed. Sunderland, MA: Sinauer Associates.

Magallón, S., Gómez-Acevedo, S., Sánchez-Reyes, L. L., \& Hernández-Hernández, T. (2015). A meta-calibrated timetree documents the early rise of flowering plant phylogenetic diversity. New Phytologist, 207, 437-453. https ://doi.org/10.1111/nph.13264

Manchester, S. R., Chen, Z. D., Lu, A. M., \& Uemura, K. (2009). Eastern Asian endemic seed plant genera and their paleogeographical history throughout the Northern Hemisphere. Journal of Systematics and Evolution, 47, 1-42. https ://doi.org/10.1111/j.1759-6831.2009.00001.x

Manchester, S. R., \& Tiffney, B. H. (2001). Integration of paleobotanical and neobotanical data in the assessment of phytogeographic history of holarctic angiosperm clades. International Journal of Plant Sciences, 162, S19-S27. https ://doi.org/10.1086/323657

Mao, K., Milne, R. I., Zhang, L., Peng, Y., Liu, J., Thomas, P., ...Renner, S.S. (2012). Distribution of living Cupressaceae reflects the breakup of Pangea. Proceedings of the National Academy of Sciences, 109(20), 77937798. https ://doi.org/10.1073/pnas.11143 19109

Maslova, N. P., Golovneva, L. B., \& Tekleva, M. V. (2005). Infructescences of Kasicarpa gen. nov. (Hamamelidales) from the late Cretaceous (Turonian) of the Chulym-Yenisey depression, western Siberia, Russia. Acta Palaeobotany, 45, 121-137.

Matzke, N. J. (2013). Probabilistic historical biogeography: New models for founder-event speciation, imperfect detection, and fossils allow improved accuracy and model-testing. Frontiers in Biogeography, 5, 242-248. https ://doi.org/10.21425/ F55419694

McLoughlin, S. (2001). The breakup history of Gondwana and its impact on pre-Cenozoic floristic provincialism. Australian Journal of Botany, 49, 271-300. https ://doi.org/10.1071/BT00023

Meseguer, A. S., Lobo, J. M., Ree, R., Beerling, D. J., \& Sanmartín, I. (2015). Integrating fossils, phylogenies, and niche models into biogeography to reveal ancient evolutionary history: The case of Hypericum (Hypericaceae). Systematic Biology, 64, 215-232. https ://doi.org/10.1093/sysbi o/syu088

Morley, R. J. (2007). Cretaceous and Tertiary climate change and the past distribution of megathermal rainforests. In J. R. Flenley, \& M. B. Bush (Eds.), Tropical rainforest responses to climate change (pp. 1-31). New York: Springer.

Nie, Z. L., Sun, H., Manchester, S. R., Meng, Y., Luke, Q., \& Wen, J. (2012). Evolution of the intercontinental disjunctions in six continents in the Ampelopsis clade of the grape family (Vitaceae). BMC Evolutionary Biology, 12, 17. https ://doi.org/10.1186/1471-2148-12-17

O'Reilly, J. E., dos Reis, M., \& Donoghue, P. C. J. (2015). Dating tips for divergence-time estimation. Trends in Genetics, 31, 631-650. https ://doi.org/10.1016/j.tig.2015.08.001

Ohsawa, M. (1991). Structural comparison of tropical montane rain forest along latitudinal and altitudinal gradients in south and east Asia. Vegetatio, 97, 1-10.

Parham, J. F., Donoghue, P. C. J., Bell, C. J., Calway, T. D., Head, J. J., Holroyd, P. A., ... Benton, M. J. (2012). Best practices for justifying fossil calibrations. Systematic Biology, 61, 346-359. https ://doi. org/10.1093/sysbi o/syr107

Posada, D., \& Crandall, K. A. (1998). MODELTEST: Testing the model of DNA substitution. Bioinformatics, 14, 817-818. https ://doi.org/10.1093/bioin forma tics/14.9.817

Pyron, R. A. (2011). Divergence time estimation using fossils as terminal taxa and the origins of Lissamphibia. Systematic Biology, 60, 466-481. https ://doi.org/10.1093/sysbi o/syr047

Ree, R. H., \& Sanmartín, I. (2018). Conceptual and statistical problems with the DEC+J model of founder-event speciation and its comparison with DEC via model selection. Journal of Biogeography, 45, 741-749. https ://doi.org/10.1111/jbi.13173

Ree, R. H., \& Smith, S. A. (2008). Maximum likelihood inference of geographic range evolution by dispersal, local extinction, and cladogenesis. Systematic Biology, 57, 4-14. https ://doi.org/10.1080/1063515070 1883881 
Renner, S. S., Strijk, J. S., Strasberg, D., \& Thébaud, C. (2010). Biogeography of the Monimiaceae (Laurales): A role for East Gondwana and long-distance dispersal, but not West Gondwana. Journal of Biogeography, 37, 1227-1238. https ://doi.org/10.1111/j.1365-2699.2010.02319.x

Ronquist, F., Teslenko, M., van der Mark, P., Ayres, D. L., Darling, A., Höhna, S., ... Huelsenbeck, J. P. (2012). MrBayes 3.2: Efficient Bayesian phylogenetic inference and model choice across a large model space. Systematic Biology, 61, 539-542. https ://doi.org/10.1093/sysbi o/sys029

Sauquet, H., Ho, S. Y. W., Gandolfo, M. A., Jordan, G. J., Wilf, P., Cantrill, D. J., ... Udovicic, F. (2012). Testing the impact of calibration on molecular divergence times using a fossil-rich group: The case of Nothofagus (Fagales). Systematic Biology, 61, 289-313. https ://doi. org/10.1093/sysbi o/syr116

Schaefer, H., Heibl, C., \& Renner, S. S. (2009). Gourds afloat: A dated phylogeny reveals an Asian origin of the gourd family (Cucurbitaceae) and numerous oversea dispersal events. Proceedings of the Royal Society B: Biological Sciences, 276, 743-851. https ://doi.org/10.1098/ rspb.2008.1447

Scotese, C. R. (2004). A continental drift flipbook. Journal of Geology, 12, 729-741. https ://doi.org/10.1086/424867

Soltis, D. E., Smith, S. A., Cellinese, N., Wurdack, K. J., Tank, D. C., Brockington, S. F., ... Soltis, P. S. (2011). Angiosperm phylogeny: 17 genes, 640 taxa. American Journal of Botany, 98, 704-730. https :// doi.org/10.3732/ajb.1000404

Stevens, P. F. (2001). Angiosperm Phylogeny Website. Version 14, July 2017 [and more or less continuously updated since]. Available at http://www.mobot.org/MOBOT/ resea rch/APweb/ .

Swofford, D. L. (2003). PAUP*: Phylogenetic analysis using parsimony (*and other methods), version 4.0b10. Sunderland, MA: Sinauer Associates.

Takhtajan, A. (1969). Flowering plants: Origin and dispersal. Edinburgh, UK: Oliver and Boyd.

Thomas, D. C., Chatrou, L. W., Stull, G. W., Johnson, D. M., Harris, D. J., Thongpairoj, U. S., \& Richard, M. K. S. (2015). The historical origins of palaeotropical intercontinental disjunctions in the pantropical flowering plant family Annonaceae. Perspectives in Plant Ecology, Evolution and Systematics, 17, 1-16. https ://doi.org/10.1016/j.ppees.2014.11.001

Thompson, J. D., Gibson, T. J., Plewniak, F., Jeanmougin, F., \& Higgins, D. G. (1997). The Clustal X windows interface: Flexible strategies for multiple sequence alignment aided by quality analysis tools. Nucleic Acids Research, 24, 4876-4882.

Tiffney, B. H. (1985). Perspectives on the origin of the floristic similarity between eastern Asia and eastern North America. Journal of Arnold Arboretum, 66, 73-94. https ://doi.org/10.5962/bhl.part.13179

Tiffney, B. H., \& Manchester, S. R. (2001). The use of geological and paleontological evidence in evaluating plant phylogeographic hypotheses in the Northern Hemisphere Tertiary. International Journal of Plant Sciences, 162, S3-S17. https ://doi.org/10.1086/323880

Upchurch, G. R., \& Wolfe, J. A. (1993). Cretaceous vegetation of the Western Interior and adjacent regions of North America. Geological Association of Canada Special Paper, 39, 243-281.

Wang, H., Moore, M. J., Soltis, P. S., Bell, C. D., Brockington, S. F., Alexandre, R., ... Soltis, D. E. (2009). Rosid radiation and the rapid rise of angiosperm-dominated forests. Proceedings of the National Academy of Sciences, 106(10), 3853-3858. https ://doi.org/10.1073/pnas.08133 76106

Wang, W., Lin, L. I., Xiang, X.-G., Ortiz, R. D. C., Liu, Y., Xiang, K.-L., ... Chen, Z.-D. (2016). The rise of angiosperm-dominated herbaceous floras: Insights from Ranunculaceae. Scientific Reports, 6, 27259. https ://doi.org/10.1038/srep2 7259

Wang, W., Ortiz, R. D. C., Jacques, F. M. B., Xiang, X.-G., Li, H.-L., Lin, L. I., .. Chen, Z.-D. (2012). Menispermaceae and the diversification of tropical rainforests near the Cretaceous-Paleogene boundary. New Phytologist, 195, 470-478. https ://doi.org/10.1111/j.1469-8137.2012.04158.x

Wickens, G. E. (1983). The baobab: Africa's upside-down tree. Kew Bulletin, 37, 173-209. https ://doi.org/10.2307/4109961

Wolfe, J. A. (1974). Fossil forms of Amentiferae. Brittonia, 25, 334-355. https ://doi.org/10.2307/2805639

Wolfe, J. A. (1975). Some aspects of the plant geography of the Northern Hemisphere during the Late Cretaceous and Tertiary. Annals of the Missouri Botanical Garden, 62, 264-279. https ://doi.org/10.2307/2395198

Wu, Z. Y., Lu, A. M., Chen, Z. D., \& Li, D. Z. (2003). The families and genera of angiosperms in China. Beijing, China: Science Press.

Xiang, X.-G., Wang, W., Li, R.-Q., Lin, L. I., Liu, Y., Zhou, Z.-K., ...Chen, Z.-D. (2014). Large-scale phylogenetic analyses reveal fagalean diversification promoted by the interplay of diaspores and environments in the Paleogene. Perspectives in Plant Ecology, Evolution and Systematics, 16, 101-110. https ://doi.org/10.1016/j.ppees.2014.03.001

Yang, Z., \& Rannala, B. (2006). Bayesian estimation of species divergence times under a molecular clock using multiple fossil calibrations with soft bounds. Molecular Biology and Evolution, 23, 212-226. https :// doi.org/10.1093/molbe v/msj024 
Ying, T. S., \& Chen, M. L. (2011). Plant geography of China. Shanghai, China: Shanghai Scientific \& Technical Publishers.

Yu, X.-Q., Gao, L.-M., Soltis, D. E., Soltis, P. S., Yang, J.-B., Fang, L., ... Li, D.-Z. (2017). Insights into the historical assembly of East Asian subtropical evergreen broadleaved forests revealed by the temporal history of the tea family. New Phytologist, 215, 1235-1248. https :// doi.org/10.1111/nph.14683

Yu, Y., Harris, A. J., Blair, C., \& He, X. J. (2015). RASP (Reconstruct Ancestral State in Phylogenies): A tool for historical biogeography. Molecular Phylogenetics and Evolution, 87, 46-49. https ://doi. org/10.1016/j.ympev.2015.03.008

Zachos, J. C., Dickens, G. R., \& Zeebe, R. E. (2008). An early Cenozoic perspective on greenhouse warming and carbon-cycle dynamics. Nature, 451, 279-283. https ://doi.org/10.1038/natur e06588

Zhang, J.-B., Li, R.-Q., Xiang, X.-G., Manchester, S. R., Lin, L. I., Wang, W., ... Chen, Z.-D. (2013). Integrated fossil and molecular data reveal the biogeographic diversification of the eastern Asian-eastern North American disjunct hickory genus (Carya Nutt.). PLoS ONE, 8, e70449. https ://doi.org/10.1371/journ al.pone.0070449

Zhang, Z. Y., \& Lu, A. M. (1995). Hamamelidaceae: Geographic distribution, fossil history and origin. Acta Phytotaxonomy Sinica, 33, 313-339.

Zhou, S. F. (1986). The Cretaceous and Tertiary Aquilapolles in China. Acta Botanica Sinica, 28, $213-223$.

\section{BIOSKETCH}

Xiaoguo Xiang is an Associate Professor in Institute of Botany, Chinese Academy of Sciences and Nanchang University. She is interested in integrating palaeontological and molecular data to investigate the biogeographic diversification of tropical plant lineages.

Author contributions: W.W. conceived and designed the experiments. K.X. performed the experiments. X.X. and K.X. analysed the data. X.X., R.C.O., F.J. and W.W. contributed to drafting and revising the manuscript. All authors read and approved the final manuscript. 


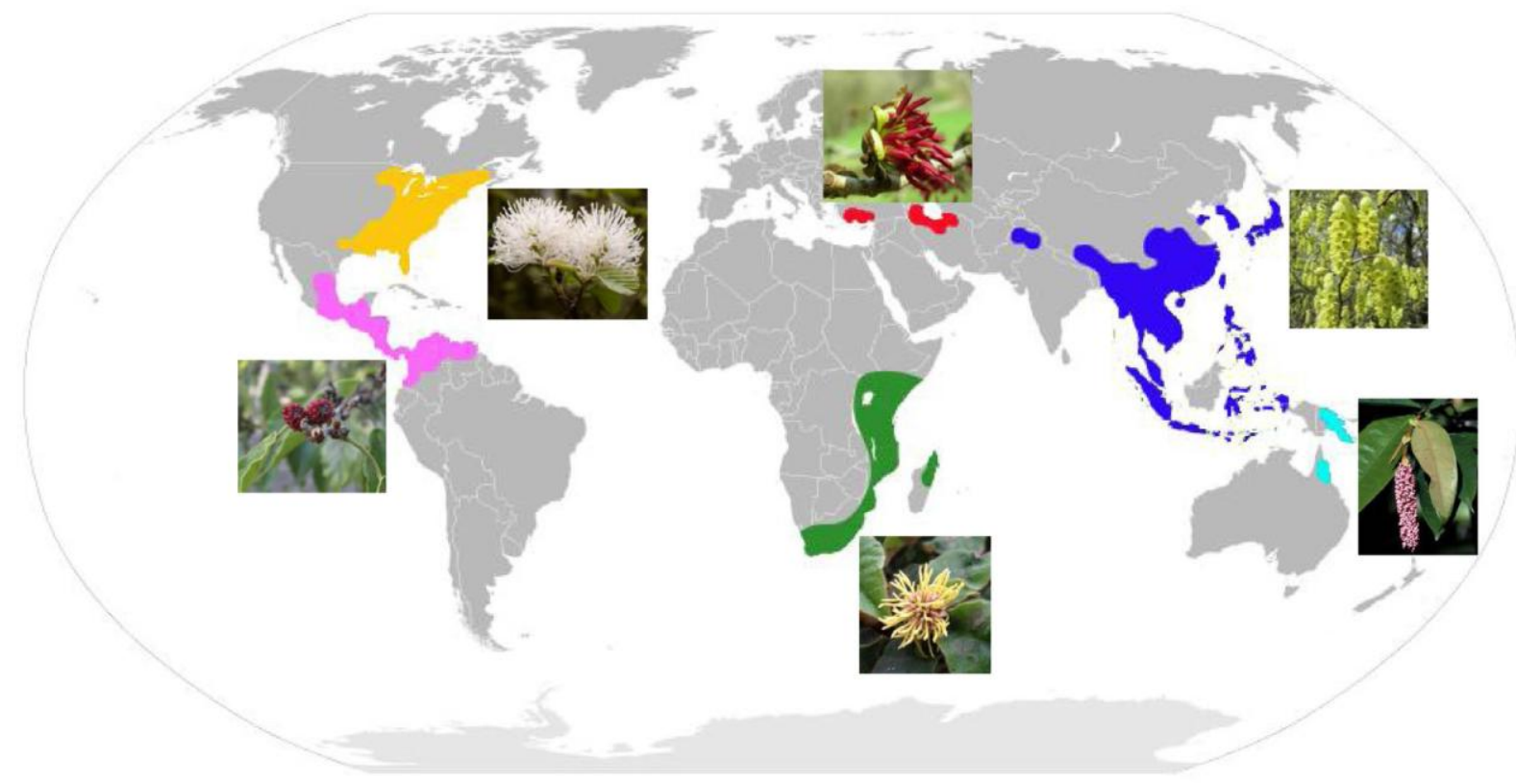

FIGURE 1 Geographic distribution of both extant and extinct hamamelidaceous species. The extant members of widespread and endemic genera (the latter in brackets) are indicated for each region. The photograph inserts are Fothergilla major (A), Parrotia persica (B), Corylopsis spicata (C), Molinadendron sinaloense (D), Trichocladus crinitus (E) and Noahdendron nicholasii (F). The fossil distributions are referred in Table S1. Photographs by S.X.Y 


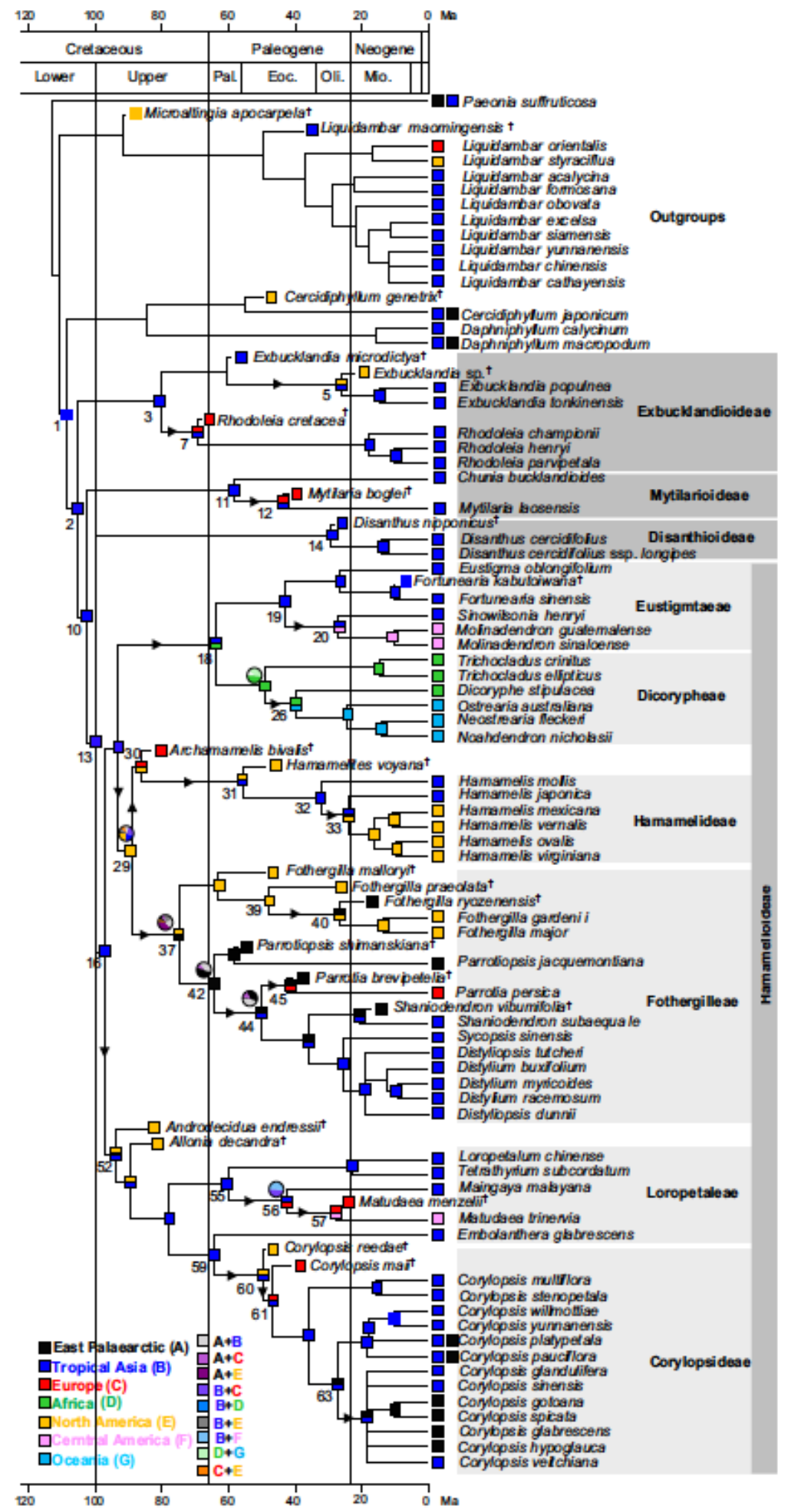

FIGURE 2 Reconstruction of the historical biogeography for Hamamelidaceae under the dispersal-extinctioncladogenesis model in Statistical BioGeoBEARS with seven defined biogeographic regions. The details of the present-day distribution of the extant species are given in Table S2. "†" indicates a fossil taxon. Numbers near the branches indicate the node number, as referred to Figures S3. Arrows show the inferred dispersal events. Boxes on each node are colour coded for the area with the highest ML probability. Pies are placed near nodes with the highest area probability less than $50 \%$. 


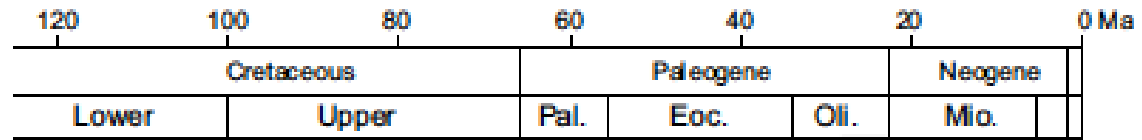

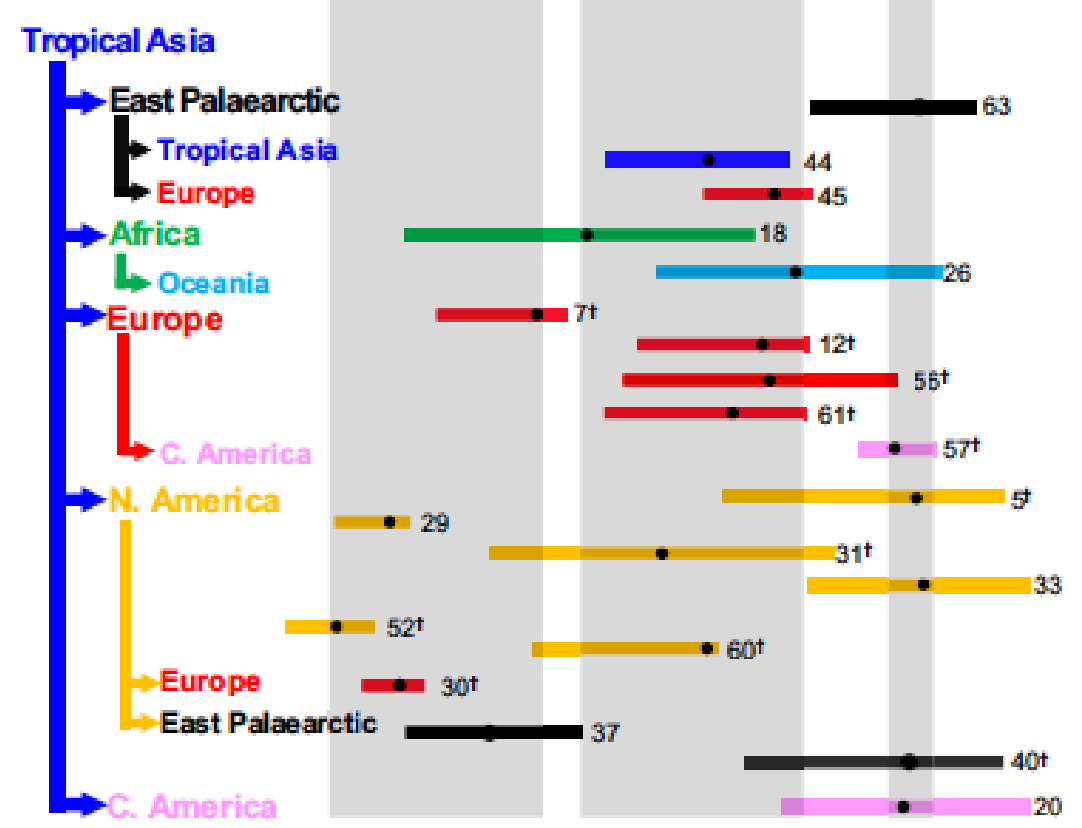

FIGURE 3 Age estimates for dispersal events in Hamamelidaceae. The inferred dispersal events between areas summarized from Figure 2 are indicated by colours (same colour coded as in Figure 1). Black dots and horizontal bars represent the median ages and 95\% highest posterior density intervals respectively. Node numbers are referred as those in Figure 2. "†" indicates a fossil taxon. The three grey areas were hypothesized as important intervals for range expansion of Hamamelidaceae. 